\title{
VISIONES DE LA CIENCIA Y LA RELIGIÓN EN LA CASA INFERNAL Y LA LEYENDA DE LA MANSIÓN DEL INFIERNO
}

\author{
RubÉN SÁnChez Trigos \\ Universidad Rey Juan Carlos / U-tad \\ rubensancheztrigos@gmail.com
}

Recibido: 15-01-2014

Aceptado: 23-04-2014

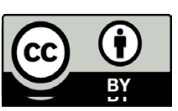

RESUMEN

La casa infernal, novela de Richard Matheson publicada en 1971, y La leyenda de la mansión del infierno, adaptación cinematográfica de la misma estrenada en 1973, mantienen un poderoso discurso, habitual en gran parte de la obra de Matheson: la confrontación entre la visión científica y la visión sobrenatural-religiosa a la hora de procesar la realidad. Asimismo, esta confrontación puede leerse también como una disección acerca de los mecanismos con los que lo fantástico se relaciona con los paradigmas culturales de cada época.

Palabras clave: Richard Matheson, La casa infernal, ciencia, religión, cine de terror, John Hough.

\section{ABSTRACT}

Hell House, Richard Matheson's novel published in 1971, and The Legend of Hell House, the film adaptation premiered in 1973, maintain a powerful discourse, common in much of the work of Matheson: the confrontation between the scientific and the supernaturalreligious visions when it comes to process reality. Likewise, this confrontation can also be read as a dissection on how the fantastic relates to the cultural paradigms of each era.

KeYwords: Richard Matheson, Hell House, science, religion, horror film, John Hough.

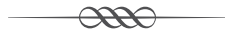




\section{INTRODUCCIÓN}

Tal y como apunta Matthew Bradley (2010: 179 y siguientes), el libreto de La leyenda de la mansión del infierno (The Legend of Hell House, John Hough, 1973) constituye el único guión escrito por Richard Matheson (1926-2013) para la gran pantalla filmado durante la década de los años setenta, período en que su escritura audiovisual se concentra, sobre todo, en la televisión, ya sea mediante tv-movies como El diablo sobre ruedas (Duel, Steven Spielberg, 1971) o series como The Night Stalker (1972-1974). Matheson pertenece así a una generación de narradores que, como Robert Bloch o Fritz Leiber, desarrolla su trabajo literario en paralelo a dos fenómenos audiovisuales muy concretos que ayudan a configurar un marco cultural del que resulta imposible disociar su obra: por un lado, la eclosión del cine de ciencia ficción que tendría lugar a lo largo de los años cincuenta, y que le proporcionará su primera oportunidad como guionista cinematográfico a través de El increíble hombre menguante (The Incredible Shrinking Man, Jack Arnold, 1957), y por otro la aparición de la televisión y su espectacular desarrollo en la sociedad norteamericana durante esa misma década y la siguiente. Se trata, pues, de una generación de escritores de naturaleza multimedia, cuya impronta literaria se encuentra poderosamente influida por el medio audiovisual con el que conviven y trabajan de una forma natural, como el propio autor llegaría a admitir: «Mi estilo siempre ha sido muy visual cuando escribo novelas o relatos. Lo veo mientras lo estoy escribiendo; el lector también lo ve, por lo tanto, mi prosa es fácil de trasladar al cine» (Matheson en McGillian, 1997: 203). La actividad de Matheson basculó de esta forma, durante toda su carrera, entre la literatura, el cine y la televisión, medios estos últimos para los que adaptó tanto obras ajenas como suyas propias a lo largo de más de cinco décadas. ${ }^{1}$ A este último apartado pertenece La leyenda de la mansión del infierno, adaptación particularmente fiel para la gran pantalla de su novela La casa infernal (Hell House, 1971), publicada apenas dos años antes de la producción del filme. Tanto la película como el original literario han merecido hasta ahora una atención crítica y académica menor que las de obras a priori más emblemáticas (y anteriores) de su autor, en especial Soy leyenda (I Am Legend, 1954) y El increíble hombre menguante (The Incredible Shrinking Man, 1956), en cuyas adaptaciones fílmicas (al menos en la primera de ellas) Matheson intervino también como guionista o co-guionista.

1 Respecto a su trabajo en series de televisión y telefilmes como The Twilight Zone (1959-1964), Kolchak: The Night Stalker (1972-1974), The Alfred Hitchcock Hour (1955-1965), entre otras muchas, véase Wiater, Bradley y Stuve (2009). 
Sin ánimo de resultar exhaustivos, algunos de los motivos que podrían explicar esta desatención podrían descansar en los siguientes aspectos.

En primer lugar, a diferencia de trabajos más populares de Matheson, La casa infernal y su versión cinematográfica se acogen a un arquetipo del género de terror, la casa encantada, para, al menos en apariencia, desarrollar un relato relativamente respetuoso con la tradición del mismo. En este sentido, si a Soy leyenda se le atribuye el mérito de disociar al vampiro de su configuración gótico-folclórica original (Waller, 1986) (firmemente asentada en el imaginario popular por la obra de Stoker) para introducirlo en el mundo cotidiano de los protagonistas y los lectores, en la historia que nos ocupa no existe una transgresión/renovación de la mitología precedente tan categórica como podía ser aquélla. Por el contrario, La casa infernal reproduce algunas de las convenciones más habituales del subgénero de casas encantadas y les depara un tratamiento hasta cierto punto canónico, mientras que al mismo tiempo, y como veremos en las líneas que siguen, desarrolla un poderoso subtexto temático, relativamente habitual en la obra de Matheson, en el que ciencia y religión aparecen confrontadas y personalizadas en los distintos personajes. En otras palabras: ni la crítica ni los aficionados al género han considerado habitualmente este relato un punto de inflexión trascendental en la evolución del arquetipo de la casa encantada, como sí pudiera serlo, por ejemplo, La maldición de Hill House (The Haunted of Hill House, Shirley Jackson, 1959), tanto en el cine como en la literatura; como consecuencia de esto, su menor impacto ha propiciado también una menor atención por parte de las distintas bibliografías.

En segundo lugar, durante el periodo en que se estrena La leyenda de la mansión del infierno tiene lugar en el cine una decisiva renovación del género de terror ampliamente documentada y abordada por muy distintos autores desde entonces, renovación de la que la película de John Hough no constituye precisamente un ejemplo, sino que, más bien al contrario, ilustra hasta cierto punto los últimos estertores de un modelo que estaba a punto de morir. Así, es casi una convención que los análisis críticos de este periodo sitúen en la segunda mitad de los años sesenta, con películas como La noche de los muertos vivientes (Night Of The Living Dead, George A. Romero, 1968), La semilla del diablo (Rosemary's Baby, Roman Polanski, 1968), La matanza de Texas (The Texas Chainsaw Massacre, Tobe Hooper, 1973) y Las colinas tienen ojos (The Hills Have Eyes, Wes Craven, 1977) el acta de nacimiento de una nueva forma de entender, producir y consumir el terror cinematográfico que ha copado la mayor parte de las bibliografías dedicadas a este período. Robin Wood (1979), por 
ejemplo, fue uno de los primeros críticos que, a finales de los años setenta, empezó a hablar de una nueva era de terror moderno, aunando las escuelas teóricas políticas y psicoanalíticas, hasta entonces disociadas, para procesar la obra de cineastas (norteamericanos) como John Carpenter, Hooper, Craven o Romero en relación al desmoronamiento psico-social de las estructuras del sistema que estaba teniendo lugar a lo largo de esos años. Andrew Tudor (1989), por su parte, cifra en estas mismas fechas el punto de inflexión de las dos grandes fases en las que él divide la historia del género: una primera fase de terror seguro y una segunda fase de terror paranoico. Finalmente, Pinedo (1996) y Modleski (1986) (esta última desde una perspectiva de género) proponen sus propios paradigmas de lo que ellas denominan la película de terror de carácter postmoderno, frente al paradigma del cine de terror clásico supuestamente dominante hasta entonces.

La leyenda de la mansión del infierno, estrenada en 1973, se encuentra así, cronológicamente, en un período de ruptura. A diferencia de otras películas mucho más estudiadas (y, en principio, mucho más influyentes en el posterior desarrollo del género), como las que acabamos de mencionar, el filme se sitúa a caballo entre dos modelos: el cine de terror clásico, que conocería sus últimos ejemplos en este periodo (con los últimos títulos importantes de estudios independientes como los británicos Hammer o Amicus, de los que el filme puede considerarse una prolongación natural), y este nuevo cine de terror moderno (o paranoico, según Tudor) al que acabamos de referirnos. Es significativo a este respecto que la película esté dirigida por un director inglés de cierta trayectoria, formado en la televisión e inserto (más o menos cómodamente) en el sistema de estudios de su país, que no en vano venía de trabajar con la Hammer en una de sus últimas producciones: Drácula y las mellizas (Twins of Evil, John Hough, 1972). La carrera de Hough durante esta década, si bien se circunscribió casi en su práctica totalidad al género fantástico, siguió ligada al sistema de estudios a través de Disney, compañía para la que filmó La montaña embrujada (Escape From the Witch Mountain, 1975) y Los pequeños extraterrestres (Return From Witch Mountain, 1978), dos títulos de adscripción familiar muy alejados del que nos ocupa, antes de derivar a la serie B más canónica en la siguiente década con Incubus (The Incubus, 1981) o Aullidos IV: Aldea maldita (The Howling IV: The Original Nightmare). Su perfil como realizador, por lo tanto, se aleja considerablemente del joven cineasta contra-cultural que se mueve en los límites del viejo sistema y que estaba renovando el género en esos momentos, para abrazar, en cambio, el de un artesano de trazas más clásicas y aparentemente 
más convencionales, aun cuando su trabajo de puesta en escena en la adaptación de La casa infernal resulte especialmente barroco. Similares conclusiones pueden extraerse también de Academy Pictures, la compañía productora detrás del filme. La película constituye la primera y única producción independiente de esta empresa, fundada por James H. Nicholson tras su salida de American International Pictures, la legendaria productora con la que Roger Corman había realizado su serie de adaptaciones de las obras de Poe en los años sesenta, escritas en su mayor parte por Matheson. Nuevamente, pues, nos encontramos ante un productor procedente del periodo clásico (siguiendo con los postulados de Tudor, el período pre-finales años 60), que habría de obtener con La leyenda de la mansión del infierno la última película de su carrera antes de morir, pero también antes de que esta forma de entender el género fuera desplazada por los nuevos éxitos cuasi-vanguardistas (o, cuando menos, ajenos al sistema de estudios, siquiera independientes) antes mencionados, acabando así con la hegemonía que el cine de terror británico había ostentado desde finales de los años cincuenta (véase, en este sentido, Pirie, 2008).

La condición de La leyenda de la mansión del infierno como película de transición entre dos modelos, o entre dos paradigmas conceptuales, le permite, en definitiva, tomar prestados aspectos tanto del cine de terror clásico como del cine de terror moderno contemporáneo para su producción, pero esta indefinición dificulta también su estudio, pues exige una metodología flexible que detecte los rasgos formales, narrativos y temáticos que certifiquen esta ambivalencia. Por otra parte, su condición como relativa rareza (o como aparente vestigio de un modelo de cine de terror en vías de extinción en el momento de su estreno) podría explicar también la escasa atención que le ha sido prestada en las bibliografías críticas sobre el género. Este artículo se propone, pues, llenar dicho vacío, detectar dichos rasgos y ponerlos en relación con ese discurso científico-religioso que subyace en el filme y que desarrolla, quizás aquí de una forma más radical que en otras obras suyas, una de las líneas temáticas más frecuentes en la ingente producción literaria y audiovisual de Matheson: la confrontación existencialista entre el paradigma científico y el paradigma religioso, en particular católico, a la hora de procesar la realidad; o por decirlo con otras palabras: el mismo cuestionamiento que Matheson parece hacer del propio género fantástico, al que consagró una parte importante de su carrera. 
Tanto La casa infernal como su adaptación cinematográfica narran esencialmente la misma historia: ante su inminente muerte por culpa de un cáncer que lo está devastando, el multimillonario anciano William Reinhardt Deutsch contrata los servicios de un equipo cuidadosamente seleccionado cuyo propósito es el de demostrarle o desmentir la existencia de la vida después de la muerte en el plazo de una semana. El equipo está compuesto por el doctor Lionel Barrett, prestigioso físico que ha dedicado al estudio de la psicología la mayor parte de su vida, su esposa Edith (que pasa a llamarse Anna en la versión fílmica) y dos reputados médiums: la joven Florence Tanner, espiritualista y médium mental, y Benjamin Franklin Fischer, médium físico, antaño considerado el más poderoso de Estados Unidos, retirado desde que se convirtiera en el único superviviente cuerdo de la última incursión en el lugar al que se dirigen ahora: la Casa Belasco, en Maine. Conocida por el sobrenombre de la Casa Infernal, la mansión se mantuvo durante décadas bajo la influencia de su antiguo propietario, Emeric Belasco, quien llevó a cabo en ella todo tipo de prácticas extremas: canibalismo, sodomía, orgías, etc., hasta acabar primero con la cordura y después con la vida de sus invitados. Una vez en la casa, el equipo comienza a ser testigo de lo que aparentemente son diversas manifestaciones paranormales. Poco a poco, las manifestaciones se vuelven cada vez más agresivas para con los visitantes, al tiempo que Barrett ve en éstas una oportunidad para probar sus teorías: de acuerdo con ellas, lo que habitualmente se consideran fenómenos paranormales son producidos en realidad por la energía electromagnética que emiten todos los seres vivos y que queda contenida en ellos sin disiparse, hasta el instante de su muerte. Barrett espera demostrarlo mediante una máquina de su invención, el Reversor, con la que intentará absorber la energía de la Casa Infernal y limpiarla de dichos fenómenos.

El argumento de La casa infernal y de La leyenda de la mansión del infierno bascula así alrededor de la confrontación que mantienen en particular dos personajes: el doctor Barrett por un lado, representante de una cosmovisión científica de la realidad, y la señorita Tanner por otro, quien encarna una visión sobrenatural de las leyes que rigen el mundo, entendiendo este término en su sentido etimológico; es decir, tal y como advierte David Roas (2001: 8): «la intervención de fuerzas de origen demiurgo, angélico y / o demoníaco». En efecto, Tanner codifica su habilidad para conectar con supuestas entidades desencarnadas por medio de la imaginería católica, reproduciendo así la idea cristiana del cielo, el infierno y el limbo, identificando la Casa Belasco con este 
último: un espacio liminal donde los espíritus deben purgar sus pecados y entrar en paz consigo mismo antes de acceder a un nivel superior de conciencia. Barrett, por el contrario, identifica dichas entidades con residuos de energía electromagnética producidos por el cuerpo humano de forma natural y científicamente explicable; es decir, racionaliza las creencias de Tanner a partir de postulados propios de la física (o, cuando menos, de una seudo-física que, más la novela que la película, se entrega a defender).

Como sostiene Cristopher M. Moreman (2012), ésta es una constante temática habitual en una buena parte de la narrativa fantástica de Matheson: por ejemplo, aparece en relatos como «La casa Slaughter» («Slaughter House», 1953) o «Vestido de seda blanca» («Dress of White Silk», 1951), donde sugiere alternativas racionales a motivos sobrenaturales comunes del género como la casa encantada o el mito del vampirismo, o en la novela En algún lugar del tiempo (Bid Time Return, 1975), donde propone una alternativa a caballo entre la ciencia y la fe en lo sobrenatural para los viajes en el tiempo: la idea de que la mente humana posea la facultad natural de desplazarse entre las diferentes épocas mediante la concentración adecuada. Pero probablemente sea en Soy leyenda donde la confrontación entre la visión de la ciencia y la del mundo sobrenatural-religioso se haga más palpable, hasta conformar, como apuntábamos, una profunda y muy influyente revisión de la figura del vampiro. Así, si como señala Hjelm (2009: 105-121), el vampiro se ha ido alejando cada vez más de sus raíces explícitamente sobrenaturales para someterse a un proceso de racionalización más acorde con las sensibilidades seculares modernas, en Soy leyenda Matheson prefigura este proceso con la historia de Robert Neville, el último superviviente de un mundo dominado por seres humanos infectados que muestran los síntomas de lo que la cultura popular ha tomado por vampiros. De hecho, Neville trata al principio de combatir a los monstruos mediante los recursos que el cristianismo pone en sus manos, en especial en lo que se refiere al poder de la cruz católica. Sin embargo, dichos recursos se muestran ineficaces con algunos de ellos, y Neville se entrega a la búsqueda de una explicación científica (algún tipo de virus que les haga vulnerables al sol y al ajo), para finalmente acabar con una revelación que concilia, en cierto modo, las dos posiciones: la cruz sólo afecta a aquellos individuos que, antes de ser infectados, ya tenían convicciones cristianas. De este modo, Matheson muestra cómo el poder de la religión institucionalizada arraiga en las mentes de los individuos despojándolos de la pretensión de obtener una verdad objetiva. Para Moreman (2012: 130-133), el mensaje del texto es claro y pesimista: la esperanza cristiana para la salvación es vana; el poder de la cruz no es nada más que una ilusión neurótica, 
y en ese engaño todas las religiones establecidas son iguales. No es de extrañar, por lo tanto, que la segunda adaptación cinematográfica de la novela, El último hombre... vivo (The Omega Man, Boris Sagal, 1971), convierta a los infectados en una suerte de secta apocalíptica ataviada con una indumentaria de túnicas de trazas seudo-monacales. No obstante, la posición de Matheson respecto al poder de la ciencia no es mejor, y resulta también ambigua: como sucede en $\mathrm{El}$ increíble hombre menguante, en Soy leyenda también la ciencia se muestra inoperante para resolver los problemas de Neville; problemas que ostentan una naturaleza más humana, más cerca del relativismo y/o de la filosofía existencial: su incapacidad para aceptar el surgimiento de un nuevo Orden distinto al suyo, pero a la vez tan humano como éste. Además, es la misma ciencia la que parece encontrarse en el origen del virus que ha devastado a la humanidad, aspecto éste ampliamente potenciado en las adaptaciones cinematográficas. Ciencia y religión se homologan así como dos medios canónicos de procesar la realidad que terminan revelándose incompletos para este objetivo: en última instancia, sólo las emociones humanas, expuestas de un modo desnudo y descarnado, constituyen una respuesta valida a los problemas del individuo, parece decirnos Matheson. Esta ambivalencia paradójica, teñida de un cierto nihilismo, articula también el subtexto temático y el retrato de los personajes que realizan tanto La casa infernal como su adaptación La leyenda de la mansión del infierno, de una forma posiblemente menos sofisticada y al mismo tiempo más cáustica de lo que sucede en Soy leyenda, como veremos en el resto de este artículo.

3. El CONFLICTO DE LO FANTÁSTICO EN LA CASA INFERNAL Y LA LEYENDA DE LA MANSIÓN DEL INFIERNO

En La casa infernal y en su (inmediata) versión cinematográfica, Matheson y Hough retratan la contienda entre la visión científica y la visión religiosa-sobrenatural mediante una estrategia que personifica estas dos posiciones en los personajes de Barrett y Tanner; estrategia que relega a Edith y a Fischer a la categoría de meros actantes al servicio de dos funciones narrativas muy concretas: en el caso de Edith ilustrar la ¿auto? represión sexual a la que se somete su marido, quien llega a racionalizar su relación matrimonial hasta el punto de neutralizar este aspecto de la misma; ${ }^{2}$ en el caso de Fischer, además

2 En la novela, se cuenta que Barrett es impotente a causa de la polio. En la película está referencia es suprimida, siendo representado como un personaje que simplemente no muestra interés alguno por el sexo, posición que refuerza gracias al drama personal de su esposa, quien fuera violada por su padre de niña, desarrollando así una fobia hacia las relaciones sexuales. 
de ejercer una función narrativa común en el género (en tanto único superviviente de la anterior incursión, prefigura la magnitud de la amenaza que está por venir), constituye el cabal contrapunto de Tanner: como ella, él también codifica los fenómenos que tienen lugar en la casa mediante un prisma sobrenatural (aunque no necesariamente católico, ni siquiera religioso); sin embargo, a diferencia de Tanner, Fischer no confía ni en el poder de Dios ni en sus propias habilidades para enfrentar dichos fenómenos. En consecuencia, se presenta como un personaje pasivo (dominado por su adición al café y al alcohol) hasta el desenlace del libro, cuando, muertos ya Barrett y Tanner, es decir, eliminadas las posiciones extremas que ambos encarnan, afronta el misterio de la casa con una solución que concilia estas dos visiones. Hasta entonces, la trama se articula a través de la alternancia de dos tipos de escenas perfectamente diferenciadas: por un lado, los ataques, aparentemente sobrenaturales, que experimenta el grupo, pero sobre todo Tanner y Barrett, y por otro aquellas escenas en las que el científico y la médium discuten tratando de defender cada uno su propia posición acerca de la naturaleza de dichos ataques. En este sentido, tanto la novela como la película están plagadas de largos diálogos (mucho más desarrollados en el caso del texto) en los que los dos personajes exponen su visión ante el otro, no ya de los fenómenos que tienen lugar en la Casa Belasco, sino de la realidad propia y de su forma de aproximarse a ella. Sirva como ejemplo el siguiente diálogo, que se desarrolla al poco de que el grupo llegue al emplazamiento supuestamente encantado:

-Puede decir que es una noción fascinante, doctor -continuó-. Sin embargo, estoy segura de que es mucho más que eso. ¿Qué me dice de aquellas religiones que aceptan que hay vida después de la muerte? ¿Acaso no recuerda estas palabras de San Pablo: «Si los muertos no se levantaran de la tumba, nuestra religión sería vana?».

Barrett no contestó.

-Pero usted no lo cree -añadió Florence.

-No, no lo creo.

- ¿Y podría ofrecernos una alternativa?

-Sí -Barrett le devolvió la mirada, desafiante-. Una alternativa mucho más interesante, pero también más compleja y exigente. El ego subliminal: esa vasta y oculta extensión de la personalidad humana que, al igual que un iceberg, forma parte del supuesto umbral de la conciencia. Ahí es donde radica la fascinación, señorita Tanner. No en los reinos especulativos del más allá, sino del aquí, del hoy; el desafío de nosotros mismos. Los misterios desconocidos del espectro humano, las capacidades infrarrojas de nuestro cuerpo, las capacida- 
des ultravioletas de nuestra mente. Ésa es la alternativa que ofrezco: las extensas facultades del sistema humano que todavía no han sido demostradas. Las facultades mediante las cuales, estoy convencido, se producen todos los fenómenos psíquicos (Matheson, 2011: 55).

Mediante esta confrontación (dogma religioso frente a marco empírico), puede decirse que tanto La casa infernal como La leyenda de la mansión del infierno indagan en la verdadera naturaleza del fantástico como género y como efecto, en tanto a la relación (siempre mutable) que este mantiene con la realidad (entendiendo esta como una construcción cuya interpretación también puede transformarse). Como Roas (2011: 5) sostiene, lo fantástico propiamente dicho nació en el siglo xVIII, «en un universo newtoniano, mecanicista y que, por ello, era susceptible de explicación racional». Es decir, en un mundo donde el racionalismo aparece para explicar una realidad que hasta entonces era codificada a través de tres vías hasta cierto punto contrapuestas: la ciencia, la religión y la superstición. Así, una vez que el desarrollo del paradigma científico, a través del mecanicismo, se traduce en una escisión, aparentemente irreconciliable, entre razón y fe, la ficción procede a dar respuesta a un nuevo interés estético en lo sobrenatural, lo horrendo y lo terrible «como fuente de deleite y de belleza» (Roas, 2011: 17), que el hombre parecía demandar de una forma natural desde el momento en que la existencia de espectros, demonios y otras entidades sobrenaturales es puesta en cuestión. Un proceso que encuentra su traducción en las primeras manifestaciones de la novela gótica y en el que los románticos tienen mucho que ver: «los románticos, sin rechazar las conquistas de la ciencia, postularon que la razón, por sus limitaciones, no era el único instrumento de que disponía el ser humano para captar la realidad. La intuición y la imaginación podían ser otros medios válidos para hacerlo. Después de todo, el universo no era una máquina, sino algo más misterioso y menos racional, como debía de serlo también la mente humana» (Roas, 2011: 19). No es de extrañar que el romanticismo prefigure consistentemente el género gótico y el género de terror, así como lo fantástico, susceptible de insertarse en uno y en otro.

Lo fantástico, pues, plantea en su misma razón de ser una discusión acerca de las herramientas con las que la sociedad de cada tiempo interpreta su entorno, de forma que, como Susana Reisz (2001: 84) asevera, «puede ser tratado así como la descripción de ciertas actitudes mentales». El relato fantástico, añade, utiliza los marcos sociológicos y las formas del entendimiento que definen los dominios de lo natural y lo sobrenatural, de lo trivial y lo ex- 
traño, «no para inferir alguna certeza metafísica sino para organizar la confrontación de los elementos de una civilización relativos a los fenómenos que escapan a la economía de lo real y de lo "surreal", cuya concepción varía según las épocas» (Reisz, 2001: 85). En otras palabras: «no contradice las leyes del realismo literario, pero muestra que esas leyes se convierten en las de un irrealismo cuando la actualidad es tenida como totalmente problemática» (2001: 87). Barrett y Tanner son incapaces de ponerse de acuerdo (incluso cuando Tanner, en un momento dado, insta al científico a buscar una posición común) en tanto ambos encarnan funciones arquetípicas de las visiones que defienden. En efecto, el esquematismo con que esta confrontación es representada puede ser entendido como expresión de esa funcionalidad narrativa al servicio de un horizonte de expectativas genéricas que tradicionalmente se le ha atribuido a la narrativa popular (Palmer, 1991: 113-116); sin embargo, Barrett y Tanner personalizan la propuesta temática del relato de un modo que no parece arbitrario, teniendo en cuenta la conexión de esta propuesta con el resto de la obra de Matheson. Así, novela y película visualizan el conflicto inherente al fantástico subrayando constantemente que lo que los personajes defienden no es tanto una solución al enigma de la casa propiamente dicho, como una idea de realidad concordante con lo que su horizonte cultural les insta a creer.

Dicho conflicto transciende las escenas en las que el científico y la médium se enfangan en sus discusiones para empañar, en general, todos los demás aspectos expresivos del relato; así, en la adaptación cinematográfica, pasa a expresarse no sólo en el plano del guión sino también mediante la muy barroca puesta en escena de Hough. Ya las primeras escenas del filme apuntan el discurso que va a dominar el resto del metraje. La leyenda de la mansión del infierno se inicia con la siguiente cita, en letras blancas sobre fondo negro, de Tom Corbett, a quien se identifica como «Clarividente y físico»: «Aunque el argumento de esta película es ficticio, los hechos que en ella se describen, referentes a fenómenos psíquicos, no solamente están dentro de lo posible, sino que muy bien pudieran ser verdaderos». A continuación, la película corta a un plano general de un gigantesco fresco religioso, de motivos cristianos, pintado en el interior de una cúpula, que enseguida se identificará como parte de la casa de Deutsch. Este plano, aparentemente objetivo, se convierte en el punto de vista implícito de Edith, quien, mediante una panorámica pasa a ocupar el cuadro y, a continuación, se sienta junto a su marido, el doctor Barrett. A través de un sencillo movimiento de cámara, el científico, pues, ha ocupado el espacio que antes ocupaba el fresco religioso. Este montaje, sobre el que em- 
piezan a pasar los primeros títulos de crédito, permite al filme introducir el tema de la confrontación ciencia/religión mediante dos estrategias: por un lado, enfrentando, con la planificación, la imaginería católica y los postulados científicos encarnados en la imagen de Barrett; por otro, sugiriendo las creencias religiosas de Deutsch, cuya mansión, como la película acaba de mostrar, se encuentra decorada con suntuosos motivos cristianos. Es significativo entonces que, en la siguiente escena, durante la entrevista que Barrett mantiene con el millonario, éste le deje perfectamente claro que lo que busca en la Casa Belasco son «hechos» que certifiquen la posibilidad de una vida después de la muerte, en contraposición a la fe que parece ostentar en tanto creyente cristiano. Es sólo ahora, en la inminencia de la muerte, cuando Deutsch comienza a poner en cuestión esa fe, recurriendo a cuantos medios sean necesarios (incluida la ciencia) para obtener aquello que sus creencias religiosas le han negado hasta ahora: hechos irrefutables de la existencia de un más allá. Esta escena, en la que el conflicto queda planteado, parece completarse, por lo tanto, con la cita que abría la película: tras toda una vida aferrado a una fe, Deutsch, de pronto, siente la necesidad de encontrar la Verdad, es decir, los datos empíricos que certifiquen lo prometido, pero no demostrado, por la fe cristiana.

Nuevamente, el conflicto parece centrarse en lo que un determinado marco ontológico interpreta como posible y como imposible, pues lo que Deutsch le pide a la ciencia y a la religión a las que recurre, personificadas en las figuras de los expertos que contrata, es, en definitiva, que eliminen las barreras que separan uno y otro concepto, es decir, que identifiquen como verdadero (ni siquiera como posible) lo que hasta ahora no es sino mera especulación en el caso de cierta forma de ciencia, y meras creencias (otra forma de Verdad) en el caso de la religión. Hasta qué punto esta exigencia de Verdad condiciona el tratamiento de lo fantástico que deparan tanto la novela como la película es algo para lo que, una vez más, la discusión de Reisz acerca de las ficciones fantásticas y su relación con otros tipos de ficciones puede arrojar algo de luz. Reisz hace suya la hipótesis de A.M. Barrenechea cuando afirma que «la poética de la ficción fantástica exige tanto la coexistencia de lo posible y lo imposible dentro del mundo ficcional cuando el cuestionamiento de dicha coexistencia» (Reisz, 2001: 195-196). La cuestión radica, entonces, en «aclarar el carácter específico de esas dos modalidades en conflicto, su relación con cierta noción de realidad históricamente condicionada» (Reisz, 2001: 196). Para ello, Reisz apela a la definición de lo imposible aportada por Irene Bessière, para quien este concepto se caracteriza por un «maravilloso súbitamente improbable», delimitado, necesariamente, por dos condiciones. La primera 
de ellas es que está en contradicción con cualquiera de las leyes que integran el contexto de causalidad en que se fundan las acciones de los miembros de una comunidad cultural marcada por el racionalismo iluminista, que se afana por mantener una nítida separación entre lo natural y lo sobrenatural. La segunda de las condiciones es que no se deja reducir a un Prv («posible según lo relativamente verosímil») codificado por los sistemas teológicos y creencias religiosas dominantes, es decir, no admite su encasillamiento en ninguna de las formas convencionalmente nítidas de manifestación de lo sobrenatural en la vida cotidiana (Bessière, en Reisz, 2001: 196).

Frente a esto, lo imposible postulado en La casa infernal y en La leyenda de la mansión del infierno no parece tal, si se toma desde el punto de vista de Deutsch, Barrett o Tanner. El primero se sitúa en una posición dubitativa (no sabe qué creer, aunque desea creer) a la espera de respuestas; el segundo mantiene hasta (casi) el último instante de su vida la convicción científica que explica los supuestos fenómenos supranaturales a partir de residuos de energía electromagnética generados por el cuerpo humano; mientras que Tanner se mantiene firme en sus creencias y evita considerar las manifestaciones sobrenaturales como otra cosa que no sea una expresión de la vida después de la muerte según el dogma cristiano. Dicho de otro modo: para ninguno de estos personajes existe lo imposible tal y como Reisz y Bessière lo consideran; antes bien, cada uno de los personajes (pero muy especialmente Barrett y Tanner) dispone de su propio punto de vista (ese «posible según lo relativamente verosímil»), a través del cual procesan y moldean la realidad según sus respectivos dogmas. Ese punto de vista anula, entonces, la distinción entre lo natural y lo sobrenatural con respecto a los fenómenos psíquicos que tienen lugar en la casa: para Barrett, dicha distinción es inoperante, en tanto racionaliza dichos fenómenos mediante su propia teoría física, y para Tanner la existencia de un mundo «oculto» que coexista con el natural es perfectamente plausible según las leyes de Dios. Tanner, pues, codifica los fenómenos a partir de lo que podríamos llamar un maravilloso cristiano. A la luz de esto, resulta problemático hablar de lo fantástico intratextualmente en este relato, según Roas y otros teóricos lo han definido, es decir, como un fenómeno aparentemente imposible que irrumpe en el mundo cotidiano de los personajes y del lector/ espectador para subvertir las certezas con las que estos han construido la realidad (Roas, 2011: 14). Esto es así desde el instante en que, como estamos viendo, los dos personajes protagonistas rechazan la mera noción de lo imposible a cambio de defender sus propias posiciones, es decir, que no llegan en ningún momento a cuestionarse la idea de realidad en la que viven. 
Es en este punto donde el relato, ya sea en su original literario o en su versión cinematográfica, conecta con la constante temática ya apuntada en la obra Matheson: en la ambivalencia con que el autor evita posicionarse a la hora de dar una respuesta extratextual a los fenómenos que está representando, arrojando, en cambio, una tesis mucho más humanista, en directa relación con las emociones de los personajes y de los lectores/espectadores antes que con su percepción objetiva: así, el final del relato en la novela y en el guión no difiere demasiado, en realidad, de su homólogo en Soy leyenda. Una vez que Barrett y Tanner han muerto, supuestamente a manos del espíritu de Belasco, sólo quedan Fischer y Edith (esta última, notablemente mermada) para resolver el misterio de la casa. Será Fischer, entonces, quien accederá a la solución final, cuando descubra que, tras la capilla que Belasco hizo construir en la casa, se encuentra el verdadero secreto de la misma: una habitación cuyas paredes, suelo y techo se encuentran revestidos de plomo. En ella Fischer y Edith hayan el cuerpo auto-momificado de Emeric Belasco, en realidad un hombre de corta estatura (no un gigante, como cuentan las crónicas), que, acomplejado por ello, ordenó extirparse quirúrgicamente las piernas y sustituirlas por unas prótesis mayores. Como el propio Fischer llega a verbalizar, esta solución al enigma podría conciliar las posiciones defendidas por Barrett y Tanner a lo largo de los días anteriores: existe, en efecto, una vida después de la muerte, tal y como la médium creía, una existencia que, otorgando la razón al científico, se encuentra vinculada a la energía electromagnética.

-Puede que, al fin y al cabo, fuera un genio. -Recorrió la sala tocando todas las paredes y examinando el techo y la puerta. Entonces dijo, con temor reverencial-. Acabamos de resolver el último misterio. Su poder no era tan grande como para resistirse al Reversor. Sin embargo, hace más de cuarenta años, ya sabía que existía una relación entre la radiación electromagnética y la vida después de la muerte. Las paredes, la puerta y el techo están revestidas de plomo (Matheson, 2011: 305).

Mediante esta solución conciliadora, Matheson evita tomar partido en la confrontación mantenida entre ciencia y sobrenatural-religioso a lo largo de su relato; sin embargo, no puede evitar juzgar esta contienda desde un punto de vista moral. El hecho de que los únicos personajes que son destruidos por las fuerzas de la casa sean, precisamente, Barrett y Tanner, no es casual, como no lo es la posición adoptada por Edith y, muy especialmente, por Fischer, quienes, por lo general, mantienen una actitud equidistante, prudente y abierta ante lo que está ocurriendo a su alrededor. Lo importante, parece sugerir 
Matheson, no radica en la naturaleza final de los fenómenos de la Casa Belasco, sino en la única forma en que estos podían ser confrontados: mediante la cohesión personal y humana de todos los personajes y, muy especialmente, mediante el diálogo (que nunca llega a darse) entre los dos dogmas defendidos, como el mismo Fischer llega a explicar:

-Los esfuerzos de su marido debilitaron el poder de Belasco y los esfuerzos de Florence nos guiaron hacia la respuesta final. Yo me he limitado, simplemente, a pulirla... y me habría resultado imposible si usted no me hubiera salvado la vida. Supongo que tenía que ser así -continuó-. La lógica de su marido ayudó, pero no bastaba por sí sola. La espiritualidad de Florence también ayudó, pero tampoco bastaba por sí sola. Era necesario un elemento más, que fue el que yo proporcioné: el deseo de enfrentarme a Belasco según sus propias condiciones y derrotarlo con sus propias debilidades (Matheson, 2011: 305).

La posición de Matheson es clara: al igual que en el desenlace de Soy leyenda, castiga la incapacidad del individuo para confraternizar con el otro, para asumir las debilidades de sus propios dogmas y abrazar las fortalezas de los de los demás, buscando puntos de acuerdo comunes que faciliten la coexistencia de posiciones aparentemente irreconciliables. No es de extrañar que el grueso de los ataques sobrenaturales que experimentan los personajes se concentren en Barrett y Tanner, y que la naturaleza de esos ataques consista, esencialmente, en atacar las convicciones defendidas de forma tan vehemente por uno y por otro. Así, en el caso de Tanner es significativo que sea agredida sexualmente una y otra vez, mientras intenta aproximarse a las supuestas entidades descarnadas de la casa mediante una estrategia de amor cristiano. Esto, por supuesto, llega a su cénit en la escena de la violación, notablemente atenuada en la película con respecto a lo narrado en la novela. En ella, Tanner accede a salvar el alma del supuesto hijo de Belasco, Daniel, entregando su cuerpo al mismo, ofrecimiento que termina con una posesión/ violación por parte del supuesto espíritu (es decir, con una agresión que pervierte los fundamentos espirituales del acto que Tanner pretendía llevar a cabo). «Luche contra eso», le pide Fischer cuando ella ya ha sido poseída y trata de entregarse a él sexualmente. «¿Contra qué? ¿Contra el amor que siento hacia los hombres?», responde Tanner lascivamente, en una clara maniobra de perversión de aquello que ha defendido durante toda su vida. Del mismo modo, no menos significativo resulta que los murales católicos de la capilla se encuentren profanados con todo tipo de escenas blasfemas que, una vez más, suponen un ataque frontal contra las creencias religiosas que 
ella mantiene, incluyendo la profanación sexual de un Cristo. En la misma línea, las ofensivas contra Barrett se concentran en tambalear su visión (aparentemente segura) racionalista y empírica del mundo. Ante el ataque que sufre en la sauna, Barrett intenta contrarrestar lo que ve con una actitud serena y razonable, esforzándose por racionalizar lo que sus sentidos le indican que está ocurriendo. Más tarde, Barrett será progresivamente vapuleado, física y psicológicamente; sin embargo, Belasco (o la casa) se reserva para el final la mayor de las agresiones que puede deparar al científico: permite que el Reversor actúe en la casa, eliminando la energía electromagnética de la misma, sólo para después restablecerla y demostrarle no sólo el fracaso de su teoría, sino, muy especialmente, lo vano de dos décadas dedicadas a la ciencia. «No», exclama Barrett cuando las agujas de los medidores vuelven a ponerse en marcha. «iEs mentira, mentira, mentira!»; «iEsto no puede estar pasando!», negando justamente aquello que ha sustentado su trabajo a lo largo de su carrera como físico: las evidencias. En esta misma dirección se puede entender también el hecho de que, en varias escenas, la casa posea a Edith, obligándola a entregarse sexualmente a Fischer y a su propio marido de una forma virulenta y enfermiza, hasta el punto de que intenta forzar a este último a mantener relaciones con ella mientras se encuentran encerrados en la sauna («Ponla dura», llega a exigirle violentamente). La casa utiliza así a Edith no para destruirla a ella, sino para mermar las defensas psicológicas de Barrett, incidiendo de nuevo en lo inútil de su entrega incondicional a la ciencia, en detrimento del resto de parcelas vitales. Matheson se revela, de este modo, relativamente indulgente con aquellos personajes cuya actitud ante lo extraordinario resulta permeable a la opinión de los demás, mientras que castiga duramente la intransigencia hermética mostrada por Barrett y Tanner en sus respectivos dogmas.

\section{Conclusiones}

La casa infernal y La leyenda de la mansión del infierno articulan el mismo discurso temático: el enfrentamiento que mantienen la visión científica y la visión religiosa desde que la irrupción del racionalismo en el siglo xviII pusiera en cuestión la concepción sobrenatural de la realidad postulada por la religión y la superstición. Este discurso se lleva a cabo a través de dos estrategias: por un lado, personificando estas dos posiciones en las figuras de Barrett, un físico convencido de que cualquier fenómeno paranormal tiene en 
realidad una explicación electromagnética, y Tanner, una médium espiritual de sólidas convicciones cristianas que considera dichos fenómenos como una expresión más de la vida después de la muerte según las leyes de Dios; por otro lado, cuestiona la propia función de lo fantástico mediante la visión que estos personajes mantienen de la realidad: dado que para ninguno de ellos los fenómenos que tienen lugar en la Casa Belasco, supuestamente encantada, tiene una explicación sobrenatural, sino física o divina, lo fantástico como tal, en tanto fenómeno imposible que pone en duda esa construcción que llamamos realidad, no tiene sentido.

Frente a estas dos posiciones, cuya confrontación sustenta la mayor parte del relato literario y fílmico, Matheson evita tomar partido, postulando en cambio una solución conciliadora presente también en gran parte de su obra, especialmente en Soy leyenda: así, Barrett y Tanner mueren al final de la narración, sumidos cada uno en sus propias convicciones, mientras que Fischer y Edith, los otros dos personajes restantes, viven para desvelar el enigma de la casa: Emeric Belasco, en realidad, se hizo auto-momificar en una habitación de su mansión revestida de plomo, con el fin de intensificar la energía electromagnética irradiada por su espíritu después de su muerte. Esta solución integra, pues, las visiones científicas y sobrenatural-religiosas defendidas por Barrett y Tanner. En este sentido, y como ocurre en Soy leyenda, Matheson parece cuestionar la capacidad del individuo para hacerse entender con sus semejantes, para dialogar con quien piensa diferente a él. En cambio, son precisamente Fischer y Edith, aquellos que han mantenido una actitud conciliadora y abierta durante la narración, quienes resultan victoriosos de su incursión en la casa maldita.

BiBLIOGRAFÍA

Bradley, Matthew R. (2009): Richard Matheson On Screen, McFarland, Jefferson, North Carolina.

HJelm, Titus (2009): «Celluloid Vampires. Scientization, and the Decline of Religion», en C. Partridge y E. Christianson (eds.), The Lure of the Dark Side: Satan and Western Demonology in Popular Culture, Equinox, Londres, pp. 105-112.

Matheson, Richard (2011): La casa infernal, Minotauro, Madrid.

McGillian, Patrick (1997): Backstory 3, University of California Press, California.

Modleski, Tania (1986): «The Terror of Pleasure: The Contemporany Horror Film and Postmodern Theory», en Tania Modleski (ed.), Studies in Entertainment: Critical Approaches to Mass Culture, Indiana UP, Bloominton, pp. 155-166. 
Moreman, Christopher M. (2012): «Let this Hell be Our Heaven: Richard Matheson's Spirituality and Its Hollywood Distortions», Journal of Religion and Popular Culture, vol. 24, núm. 1, pp. 130-147.

PAlmer, Jerry (1991): Methods, Concepts, and Case Studies in Popular Fiction, Routledge, Londres.

<http:/ /dx.doi.org/10.4324/9780203131619>

PINEDO, Isabel (1996): «Recreational Terror: Postmodern elements of the contemporany horror films», Journal of Film and Video, vol. 48, núm. 1-2, pp. 17-31.

PIRIE, David (2008): A New Heritage of Horror: The English Gothic Cinema, I.B. Tauris, Londres.

ReIsz, Susana (2001): «Las ficciones fantásticas y sus relaciones con otros tipos ficcionales», en David Roas (ed.) Teorías de lo fantástico, Arco/Libros, Madrid, pp. 193221.

RoAs, David (2001): «La amenaza de lo fantástico», en David Roas (ed.) Teorías de lo fantástico, Arco/Libros, Madrid, pp. 7-44.

(2011): Tras los límites de lo real. Una definición de lo fantástico, Páginas de Espuma, Madrid.

Tudor, Andrew (1989): Monsters and Mad Scientists: A cultural history of the horror film, Blackwell, Oxford.

WALLER, Gregory (1986): The Living and the Undead: From Stoker's «Dracula» to Romero's «Dawn of the Dead», University of Illinois Press, Urbana.

Wiater, Stanley, Matthew Bradley y Paul Stuve (eds.) (2009): The Twilight Zone and Other Zones: The Dark Worlds of Richard Matheson, Kensington Publishing Corporation, Nueva York.

Wood, Robin (1979): American Nightmare: essays on the horror film, Festival of Festivals, Toronto. 